\title{
Desenvolvimento regional e a contribuição universitária: uma análise das publicações nacionais e internacionais de 2008 a 2016
}

\author{
Regional development and university contribution: an analysis of national and \\ international publications the years of 2008 and 2016
Desarrollo regional y la contribución universitaria: un análisis de publicaciones nacionales e internacionales de 2008 a 2016

\author{
Mariane Rodrigues Volz de Aguiar ${ }^{1}$ \\ Sheila Kocourek ${ }^{2}$ \\ Jairo Luz de Oliveira ${ }^{2}$ \\ Adriano Correia Rodrigues ${ }^{3}$
}

Recebido em 27/04/2018; revisado e aprovado em 08/04/2019; aceito em: 11/04/2019.

DOI: http://dx.doi.org/10.20435/inter.v21i1.1952

\begin{abstract}
Resumo: A ideia de desenvolvimento ganha força ao longo do século $X X$, a recorrente distinção entre crescimento e desenvolvimento econômico no plano histórico toma sentido a partir do entrelaçamento entre o aumento da produção e renda per capita e, ao mesmo tempo, mudanças profundas na sociedade. O tema de desenvolvimento, com enfoque para além do crescimento econômico, relacionando aspectos de qualidade de vida, sustentabilidade ambiental e equidade social e cultural, vem ganhando destaque nas discussões da área das ciências sociais. A busca por sociedades democraticamente qualificadas, atuando de forma indissociada aos interesses exclusivos da coletividade, sinaliza a necessidade de desenvolver redes de cooperação, baseadas na confiança e colaboração mútuas. Destaca-se a existência de conselhos regionais no sentido de exercer o controle social, mas também a articulação representativa e de desenvolvimento regional. Também as universidades, sobretudo as públicas, têm um compromisso social com o desenvolvimento regional; a propósito, as universidades são vetores indutores de desenvolvimento regional, conectando-se com o mundo ao mesmo tempo que se enraízam regionalmente, com efeitos na produção e no consumo da economia, que repercutem de forma multiplicadora nas estruturas espaciais, sobretudo nas cidades em que estão localizadas. Neste sentido, o estudo em tela teve como objetivo realizar um levantamento de publicações acerca da participação de universidades no processo de desenvolvimento regional, de 2008 a 2016, para analisar em quais óticas a contribuição universitária para o desenvolvimento regional vem sendo estudada. Para isso, utilizou-se a análise bibliométrica, realizada a partir da coleta de dados nas plataformas Scopus e Redalyc. Os resultados mostram que, apesar de o tema ter ganhado certa evidência no último quinquênio, ainda há carência de pesquisas que discutam com profundidade a relação das universidades como desenvolvimento regional.
\end{abstract}

Palavras-chave: análise bibliométrica; desenvolvimento regional; universidade.

Abstract: The idea of development gains strength throughout the 20th century, the recurrent distinction between growth and economic development on the historical plane makes sense from the intertwining between the increase in production and per capita income and, at the same time, profound changes in society. The development theme, with a focus beyond economic growth, relating aspects of quality of life, environmental sustainability, and social and cultural equity, has been gaining prominence in discussions in the area of social sciences. The search for democratically qualified societies, acting inseparably from the collective's exclusive interests, signals the need to develop cooperation networks, based on mutual trust and collaboration. It is worth noting the existence of regional councils in order to exercise social control, but also the representative articulation and regional development. Universities, especially public ones, also have a social commitment to regional development; by the way, universities are vectors that induce regional development, connecting with the world while taking root regionally, with effects on the production and consumption of the economy, which have a multiplying effect on spatial structures, especially in cities where are located. In this sense, the study on screen aimed to carry out a survey of publications about the participation of universities

\footnotetext{
${ }^{1}$ Instituto Federal Farroupilha (IFFAR), São Vicente do Sul, Rio Grande do Sul, Brasil.

${ }^{2}$ Universidade Federal de Santa Maria (UFSM), Santa Maria, Rio Grande do Sul, Brasil.

${ }^{3}$ Instituto Federal de Santa Catarina (IFSC), Chapecó, Santa Catarina, Brasil.
} 
in the regional development process, from 2008 to 2016, to analyze in which optics the university contribution to regional development has been studied. For that, we used the bibliometric analysis, performed from the data collection on Scopus and Redalyc platforms. The results show that, although the topic has gained some evidence in the last five years, there is still a lack of research that deeply discusses the relationship between universities and regional development.

Keywords: bibliometric analysis; regional development; university.

Resumen: La idea del desarrollo ganó fuerza a lo largo del siglo XX, la distinción recurrente entre crecimiento y desarrollo económico en el plano histórico tiene sentido por el entrelazamiento entre el aumento de la producción y el ingreso per cápita y, al mismo tiempo, cambios profundos en la sociedad. El tema del desarrollo, con un enfoque más allá del crecimiento económico, que relaciona aspectos de calidad de vida, sostenibilidad ambiental y equidad social y cultural, ha ganado importancia en las discusiones en el área de las ciencias sociales. La búsqueda de sociedades democráticamente calificadas, que actúen de manera inseparable de los intereses exclusivos de la comunidad, señala la necesidad de desarrollar redes de cooperación, basadas en la confianza y colaboración mutuas. Cabe destacar la existencia de consejos regionales para ejercer el control social, pero también la articulación representativa y el desarrollo regional. Las universidades, especialmente las públicas, también tienen un compromiso social con el desarrollo regional; por cierto, las universidades son impulsoras del desarrollo regional, conectándose con el mundo al mismo tiempo que se arraigan regionalmente, con efectos en la producción y el consumo de la economía, que tienen un efecto multiplicador en las estructuras espaciales, especialmente en las ciudades donde están ubicados. En este sentido, el estudio en pantalla tuvo como objetivo realizar una encuesta de publicaciones sobre la participación de las universidades en el proceso de desarrollo regional, de 2008 a 2016, para analizar en qué óptica se ha estudiado la contribución de la universidad al desarrollo regional. Para esto, se utilizó el análisis bibliométrico, realizado a partir de la recopilación de datos en las plataformas Scopus y Redalyc. Los resultados muestran que, aunque el tema ha ganado alguna evidencia en los últimos cinco años, todavía hay una falta de investigación que discuta profundamente la relación entre las universidades y el desarrollo regional.

Palabras clave: análisis bibliométrico; desarrollo regional; universidad.

\section{INTRODUÇÃO}

O tema de desenvolvimento regional vem ganhando cada vez mais abrangência, pois representa uma forma de proporcionar a competitividade regional, atrelada a mercados globais e sistêmicos (XAVIER et al., 2013). As primeiras discussões acerca do desenvolvimento regional consideravam principalmente fatores econômicos e o potencial de produção de valores de uma região.

Com o tempo, esse conceito passou por um processo de amadurecimento das discussões, e, hoje, define-se o desenvolvimento regional não apenas relacionado ao contexto econômico, mas estruturado pela capacidade de uma região obter crescimento econômico, seguido da melhoria na qualidade de vida, demonstrada por meio de indicadores de bem-estar econômico e social. Dessa forma, para que o desenvolvimento de uma região ocorra, pressupõe-se que os fatores ambientais, culturais, sociais, humanos e econômicos devam ser considerados, com a perspectiva de melhoria da qualidade de vida. Contudo não se despreza o fortalecimento da cadeia produtiva como dispositivo para a propulsão da cadeia produtiva (MADUREIRA, 2015).

Tratar o desenvolvimento, na visão de Chiarello (2015), significa pensar em um novo conceito de desenvolvimento, atrelando o desenvolvimento humano, o desenvolvimento social e o desenvolvimento sustentável, dinamizando a articulação desses conceitos junto ao crescimento econômico. Esses conceitos reforçam a noção de que, quanto maior for o capital humano e melhores forem as condições de vida da população, maiores serão as condições de desenvolvimento.

A propósito de desenvolvimento regional, importam as relações sociais, as estratégias de integração e um planejamento que leve em consideração um contexto específico, que se 
aliam por concentrar características similares, de modo a provocarem transformações sociais, ambientais e econômicas. É o que alguns autores denominam de desenvolvimento endógeno (VÁZQUEZ BARQUERO, 2001; XAVIER et al., 2013).

No que tange às Instituições de Ensino Superior neste processo, a região tem expectativas no que concerne ao desenvolvimento, visto que uma universidade representa difusão de conhecimento, formação de pessoas, realização de pesquisas e produção de conhecimento, bem como o diálogo entre os saberes eruditos com os populares. Portanto o potencial de intervenção é alto, sendo o papel da universidade, em alguns casos, determinante para o desenvolvimento de uma região.

Além disso, significa reforçar o contexto regional, já que estas instituições representam um espaço de articulação entre os segmentos da sociedade. Diante disso, a universidade assume a função, junto ao Estado e à sociedade, de impulsionar o desenvolvimento da região em que está inserida. O autor Etzkowitz (2005) elucida este processo referindo-se a um modelo de tríplice hélice, no qual se pode perceber uma interação entre universidade-empresa-governo, proporcionando, deste modo, um impacto relevante na economia e qualidade de vida dos sujeitos.

Considerando os pressupostos apresentados, o presente estudo teve por objetivo realizar um levantamento sobre as publicações nacionais, tendo como território a América Latina, e internacionais, levando em conta os demais países, acerca do desenvolvimento regional e a universidade, no período de 2008 a 2016, a fim de analisar em quais óticas, compreendidas estas como áreas de interesse, a contribuição universitária para o desenvolvimento regional vem sendo estudada. Será utilizado o método de pesquisa bibliométrica, definida por Araújo (2006) como uma técnica quantitativa utilizada para identificar, explicar e interpretar o desempenho da produção científica em determinada área do conhecimento.

\section{DESENVOLVIMENTO REGIONAL: ABORDAGENS TEÓRICAS CLÁSSICAS}

Para iniciar uma revisão sobre o desenvolvimento regional, primeiro se faz necessário conceituar separadamente os termos de região e desenvolvimento, a fim de compreendê-los. No âmbito de região, utiliza-se da conceituação trazida por Bassan e Siedenberg (2003), os quais ressaltam que uma região é identificada por meio da representação de seis características: (1) sua formação geomorfológica, econômico-social, histórica e cultural; (2) a distribuição espacial da população; (3) as origens do processo produtivo; (4) a base da economia local; (5) os aspectos políticos que envolvem a região; e (6) os aspectos administrativos.

Em relação aos aspectos de desenvolvimento, Dallabrida (2000) entende que este relacionase a aspectos voltados não apenas ao crescimento econômico, visão esta compartilhada por Oliveira (2002), que compreende o desenvolvimento como o resultado do crescimento econômico seguido da melhoria na qualidade de vida, considerando

[...] as alterações da composição do produto e a alocação de recursos pelos diferentes setores da economia, de forma a melhorar os indicadores de bem-estar econômico e social (pobreza, desemprego, desigualdade, condições de saúde, alimentação, educação e moradia). (VASCONCELLOS; GARCIA, 1998, p. 205 apud OLIVEIRA, 2002, p. 38).

Pode-se dizer que a discussão sobre o tema de desenvolvimento regional teve origem na ciência econômica, por meio de autores como Adam Smith, Thomas Robert Malthus, David Ricardo e John Stuart Mill, os quais problematizaram, conforme Dallabrida (2017), questões 
sobre como melhorar as condições de vida da população pelo aumento do acúmulo de riquezas. Entretanto a abordagem dos autores relaciona a qualidade de vida com o aumento de riquezas, ao determinar a riqueza das nações por meio da produtividade do trabalho útil, sendo este o que produz excedente de valor em relação ao custo de produção e à quantidade de trabalho destinada ao processo produtivo (DALLABRIDA, 2017).

No mesmo sentido, abordagens como as de Smith e Ricardo denotavam a preocupação com a estagnação da economia, apresentada por Dallabrida (2017) como o momento em que as possibilidades de crescimento seriam esgotadas e a acumulação de capital seria cessada, o que faria com que a economia deixasse de crescer. Já John Stuart Mill, segundo Dallabrida (2017), apresentava uma visão otimista em relação à estagnação da economia, também denominada estacionário, afirmando que "aperfeiçoamentos na produção, no comércio e nos serviços, decorrentes do uso mais habilidoso do capital, proporcionaria novas oportunidades para aumentar a taxa de acumulação e da produção nacional" (DALLABRIDA, 2017, p. 23).

Outro autor, de grande influência sobre a teoria do desenvolvimento é Karl Marx, o qual, segundo Sandroni (1999), construiu sua análise com base na visão de Smith e Ricardo, difundindo a teoria valor-trabalho. Sua contribuição está na diferenciação do valor quantitativo e valor qualitativo do trabalho, definindo este como o valor pelo tempo de trabalho socialmente necessário para a produção de um produto. Apesar do interesse dos autores em problematizar o desenvolvimento atrelado não somente ao crescimento econômico, mas também à qualidade de vida da população, suas abordagens remetem o desenvolvimento ao aumento de riquezas e evidencia-se a preocupação voltada ao viés do crescimento econômico.

Neste aspecto, Oliveira (2002) aponta a Carta das Nações Unidas, divulgada em 1945, como o primeiro documento de maior importância que aborda as questões sobre o desenvolvimento, concomitante à criação da Organização das Nações Unidas, qual seja, 24 de outubro de 1945, que tem por finalidade a manutenção e o melhoramento dos níveis de qualidade de vida, com o propósito de contribuir para a elevação dos níveis de desenvolvimento em todos os sentidos do termo. Diante dessa perspectiva, pode-se considerar que, em termos de desenvolvimento de uma região, são premissas básicas para este: o desenvolvimento social, ambiental, cultural, humano e econômico.

\section{O PAPEL DAS UNIVERSIDADES NO DESENVOLVIMENTO REGIONAL}

Como visto até então, para que o desenvolvimento de uma região ocorra, pressupõe-se que os fatores ambientais, culturais, sociais, humanos e econômicos devem ser considerados, com a perspectiva de melhoria da qualidade de vida. Diante disso, passa-se a compreender o papel que as instituições de ensino, neste caso em análise, as universidades, assumem diante da sociedade, com vistas a colaborar com o desenvolvimento regional.

Segundo Chiarello (2015), as universidades possuem, indiscutivelmente, papel dinamizador no processo de desenvolvimento regional. Em sua missão, assumem funções que visam, além de formar profissionais de qualidade, produzir inovação e conhecimento para a sociedade (HERNÁNDEZ-ARTEAGA; MORA-GARCÍA; LUNA, 2017). Nesse contexto, a universidade assume a função, junto ao Estado e setor produtivo, de impulsionar o desenvolvimento da região em que está inserida. Pérez e Gil (2012) contribuem no mesmo sentido, ao trazer que a universidade, como Instituição de Ensino Superior, deve conhecer e integrar sua função ao meio em que está 
inserida, de forma que venha a compreender que seu papel perante a sociedade está ligado à sua função de organização.

Dessa forma, quando se discute o papel da universidade no desenvolvimento regional, na visão de Chiarello (2015), refere-se à noção de espaço e região e ao grau de interação com os segmentos da sociedade, remetendo a uma noção de capital social que se desenvolve neste espaço. Por isso, a autora compreende que "o papel da universidade é determinante no desenvolvimento regional, na medida em que as relações estabelecidas entre os agentes universidades, empresas, sociedade civil, promovem o desenvolvimento" (CHIARELLO, 2015, p. 241).

Hernández-Arteaga, Alvarado-Pérez e Luna (2015), por sua vez, compreendem que a universidade tem a responsabilidade, em um primeiro momento, de estar na sociedade, de conhecer as suas necessidades e identificar os seus problemas, para, a partir de então, propor intervenções. Por outro lado, Olachea (2011), na releitura de Hernández-Arteaga, AlvaradoPérez e Luna (2015), aponta que as universidades são impulsionadas para a contribuição no desenvolvimento regional, voltadas a oferecer resultados econômicos para as empresas e o Estado, conforme cita:

[...] a universidade tem sido impulsionada a vincular sua participação no desenvolvimento regional, a partir de estratégias vinculadas ao desenvolvimento nos campos econômico, científico e tecnológico, com o objetivo de criar cenários para estabelecer relações frutíferas com a empresa e o Estado, para contribuir para o desenvolvimento regional. Essa contribuição não pode e não deve se restringir ao desenvolvimento econômico, deve incluir as dimensões social, cultural e ambiental. (OLACHEA, 2011 apud HERNÁNDEZ-ARTEAGA; ALVARADO-PÉREZ; LUNA, 2015, p. 100, tradução dos autores).

Entretanto, conforme a visão dos autores, a atuação da universidade no desenvolvimento regional vai além do caráter econômico, estando presente também nas dimensões de desenvolvimento social, cultural, de meio ambiente e humano. Nesse sentido, caracteriza-se a responsabilidade social da universidade diante do desenvolvimento regional, por meio da qual os autores Hernández-Arteaga, Mora-García e Luna (2017) referenciam que a universidade assume como compromisso a integração dos atores endógenos (da instituição) e exógenos (da sociedade), a fim de promover maior envolvimento com as necessidades locais.

Hernández-Arteaga, Mora-García e Luna (2017) utilizam a visão de Cecchi et al. (2011) para complementar que a universidade, além de exercer um papel de interlocutor entre os atores sociais do desenvolvimento, possui função política, a qual se traduz na busca pelo consenso entre forças e poderes sociais. Diante disso, observa-se que, além de cumprir com o seu papel historicamente proposto - o da formação profissional de nível superior -, as universidades da atualidade buscam trabalhar, de forma integrada e indissociada, o ensino, a pesquisa e a extensão, a fim de promover o desenvolvimento da região por meio da formação de atores sociais qualificados no âmbito do ensino, com potencial para pesquisa e extensão, conhecendo a realidade local.

Contudo observa-se que, na visão dos autores que discutem a relação da universidade com o desenvolvimento regional, aborda-se um modelo que é denominado por Etzkowitz (2009 apud CHIARELLO, 2015) como Tríplice-Hélice, em que se define que a base estratégica do desenvolvimento regional está na interação universidade-empresa-governo. Sendo assim, compreendendo que as universidades são as instituições que trazem a base do conhecimento, 
são nelas e por meio delas que devem ser procuradas e propostas soluções para os problemas regionais e estratégias para se utilizar dos potenciais existentes nas regiões, salientando que não se trata de uma atribuição única e exclusiva destas instituições, as quais necessitam da interação e atuação da sociedade civil e organizações locais.

\section{MÉTODO}

A presente pesquisa caracterizou-se, quanto aos objetivos, como um estudo de caráter descritivo, pois adotou o "uso de técnicas padronizadas de coleta de dados" (PRODANOV; FREITAS, 2013, p. 52), as quais serão utilizadas para registrar, analisar e ordenar os dados obtidos. Quanto ao método, será um estudo bibliométrico, definido por Araújo (2006, p. 12) como "uma técnica quantitativa e estatística de medição dos índices de produção e disseminação do conhecimento científico". Basicamente, os métodos bibliométricos são utilizados com o intuito de identificar, explicar e interpretar o desempenho da produção científica em determinada área do conhecimento, com base em critérios e filtros previamente estabelecidos pelo pesquisador, de acordo com o seu objetivo de estudo.

Para realizar a busca de artigos internacionais, optou-se por utilizar a base de dados da Scopus, a qual é considerada o maior banco de dados de citações e resumos de revistas científicas, livros e trabalhos de conferências (ELSEVIER, 2017). Na base da Scopus, foi utilizada a pesquisa denominada booleana, em que se associa mais de um termo na busca de palavras-chave. Os termos utilizados para a busca foram "regional development" (entre aspas para que a busca ocorresse pelo termo completo, e não individual) e university, as quais deveriam constar nas keywords (palavras-chave) dos documentos.

Inicialmente, foram localizados 136 documentos que atendiam aos critérios elencados acima. Com o intuito de caracterizar maior profundidade ao estudo, foram aplicados alguns filtros; o primeiro teve por objetivo delimitar o período de busca, com documentos entre os anos de 2008 (último disponível no banco de dados) e 2016. Restringiu-se o tipo de documento a article, a fim de obter somente artigos publicados. Em relação às áreas de publicação, foram selecionadas: Social Sciences; Business, Management and Accounting; e Economics, Econometrics and Finance, esta última selecionada visto que o termo de desenvolvimento regional pode estar associado ao desenvolvimento econômico regional. Após aplicação dos filtros, chegou-se a 69 artigos encontrados na busca. Obtidas essas informações, utilizou-se da ferramenta de Analyze search results, disponibilizada pelo banco de dados da Scopus, para realizar a análise dos resultados quanto à evolução das publicações por ano, universidades e país de origem.

Com o intuito de aprofundar o tema de pesquisa, buscou-se identificar os principais artigos nacionais, considerando a América Latina como referência, para comparar as áreas de interesse e abordagens de pesquisa com o tema analisado. A escolha do território da América Latina para a pesquisa nacional deu-se pelo fato de que a região engloba os países do continente americano que têm como idioma oficial aqueles derivados do latim, no caso, português, espanhol e francês. Realizou-se levantamento dos artigos compilados, no período de 2008 a 2016, na Rede de Revistas da América Latina e do Caribe, Espanha e Portugal (Redalyc). Os critérios de busca adotados foram os mesmos utilizados na plataforma Scopus, sendo adotadas na busca as palavras-chave "desarrollo regional" e universidad, bem como as áreas de publicação em Administración y Contabilidad, Economía y Finanzas e Multidisciplinarias (Ciencias Sociales). Os artigos resultantes 
da pesquisa apresentaram, pelo menos, uma palavra-chave pesquisada, ou seja, a outra palavrachave consultada está inserida como palavras-chave ou no conteúdo dos artigos. Com isso, a busca resultou em 381 artigos localizados com o tema proposto.

\section{ANÁLISE DOS RESULTADOS}

Conforme objeto do presente estudo, nesta seção serão apresentadas as informações sobre as características das publicações internacionais, quanto à evolução numérica ao longo dos anos, principais periódicos, origem dos pesquisadores no que se refere à instituição e país. Quanto à caracterização das publicações nacionais, deu-se por meio das áreas de publicação e evolução ao longo dos anos, visto que a plataforma pesquisada não gera as demais informações analisadas nas publicações internacionais. Dessa forma, a presente análise está dividida em duas etapas: a primeira diz respeito à caracterização das publicações internacionais, interpretadas com base na busca avançada da Scopus; e a segunda parte apresenta as características das publicações da América Latina, extraídas da plataforma Redalyc. Por fim, apresentam-se as principais considerações, com o intuito de discorrer sobre as contribuições que estas pesquisas apontam em relação ao tema em análise.

Cabe salientar que a plataforma Scopus é mais robusta para o gerenciamento de dados secundários, o que possibilita um maior processamento dos dados existentes no sistema, gerando gráficos quanto às citações no artigo, publicações por países, por autor, universidades entre outros. Porém a plataforma Redalyc realiza o filtro conforme as informações inseridas e gera uma tabela com o nome, autores, revista, ano e resumo, além de disponibilizar uma versão completa para download. Em decorrência disso, realizaram-se avaliações quanto ao número de publicações por ano e quantitativo de publicações por revistas, no caso da busca na Redalyc.

\subsection{Caracterização das publicações internacionais}

Após a aplicação dos filtros de pesquisa, chegou-se a 69 artigos localizados, os quais abordavam a temática de desenvolvimento regional e universidade. Utilizando a ferramenta Analyze search results, citada no método, foi possível utilizar os gráficos gerados para demonstrar os dados referentes à evolução das publicações por ano, principais publicações por autores, universidades e país de origem.

Em relação ao quantitativo de publicações por ano, foi possível identificar que, a partir de 2013, houve um crescimento linear no número de publicações. Até 2013, o número de publicações sofria oscilações: em 2008, foram localizados seis artigos; em 2009, esse número caiu para cinco; em 2010, foram registradas oito publicações; em 2011, a quantidade reduziu para sete e, em 2012, para quatro, mantendo esse mesmo número em 2013. A partir de então, iniciou-se uma crescente no número de publicações, registrando oito artigos em 2014, 11 em 2015 e atingindo o ápice de publicações em 2016, com 16 artigos publicados. Esse crescimento demonstra que o tema tem despertado o interesse entre os pesquisadores, baseado no fortalecimento do papel universitário diante da sociedade, no que tange ao desenvolvimento da região em que estas estão inseridas.

Ao analisar as fontes de pesquisa, é possível identificar os cinco periódicos que se destacam entre o comparativo do número de publicações por ano e o acumulado ao longo do período de análise. Desse modo, aponta-se que o Regional Studies é o periódico que tem mais publicações 
na área de desenvolvimento regional e universidade, com o total de oito artigos publicados. 0 periódico European Planning Studies, apesar de demonstrar decréscimo no número por não ter publicações nos anos de 2008, 2012, 2013 e 2014, é o segundo periódico com mais artigos registrados no tema pesquisado, totalizando seis publicações. Observa-se, também, que o Regional Studies, entre os cinco analisados, é o único periódico que possui ao menos um artigo publicado por ano indicado na análise. Com isso, pode-se considerá-lo referência no tema de desenvolvimento regional.

Entre as 10 universidades que mais produziram sobre o tema de desenvolvimento regional e universidade no período de 2008 a 2016, estão as instituições University of Toronto, no Canadá, e University of London, em Londres, Reino Unido, ambas com quatro artigos. Na sequência, com três artigos publicados, aparecem a University of the Free State (África do Sul) e University of Strathclyde (Reino Unido), seguidas da University of Manchester (Reino Unido), Newcastle University, United Kingdom (Reino Unido), University of London, Institute of Education (Londres, Reino Unido), Birkbeck University of London (Londres, Reino Unido), Tampereen Yliopisto (Finlândia) e Open University (Reino Unido), todas com duas publicações. Observa-se que a maioria das instituições que mais publicaram ao longo dos anos está situada no Reino Unido.

Essa constatação se confirma ao identificar na plataforma de pesquisa os países que mais publicam sobre o tema pesquisado, sendo o Reino Unido com o maior número de publicações, no total de 19, seguido dos Estados Unidos, com 12, e Espanha, com sete. Na sequência, aparecem Austrália, Canadá e Suécia, com cinco artigos publicados, Portugal e África do Sul, com quatro, e Áustria e Brasil, com três artigos publicados.

Por fim, a base de dados da Scopus possibilita também identificar as principais áreas e subáreas que abordam o tema pesquisado em suas publicações. Desse modo, identifica-se que o tema de desenvolvimento regional e universidade é discutido principalmente na área de Ciências Sociais (Social Sciences), demonstrando 75,4\% das publicações. Na sequência, aparecem as áreas de Negócios, Gestão e Contabilidade (Business, Management and Accounting), Economia, Econometria e Finanças (Economics, Econometrics and Finance) e Ciência Ambiental (Environmental Science), com 27,5\% das publicações. Com isso, observa-se que as áreas de interesse apontadas na metodologia se confirmam como as principais atuantes no tema de desenvolvimento regional e universidade.

\subsection{Caracterização das publicações nacionais da américa latina}

Conforme exposto nos critérios metodológicos, a busca na plataforma Redalyc resultou em 381 artigos localizados com o tema proposto, concentrados nas áreas de Administración y Contabilidad, 162 artigos; Economia y Finanzas, 44 artigos; e Multidisciplinarias (Ciencias Sociales), 175 artigos encontrados. A análise das informações demonstra que a disciplina de economia e finanças não apresenta uma regularidade nas publicações relacionadas ao desenvolvimento regional associado à universidade, obtendo maior número de publicações no ano de 2015.

A próxima análise realizada diz respeito à revista de maior publicação na disciplina de economia e finanças, sendo esta a Estudios de Economía Aplicada, da Espanha, com seis. Próximo a este número, há três outras revistas, Revista Venezolana de Análisis de Coyuntura, Revista Facultad de Ciencias Económicas e Revista de Contabilidad, respectivamente da Venezuela, Colômbia e Espanha, todas com quatro publicações. 
Quanto às publicações de artigos na área de Ciências Sociais, observa-se a maior produção concentrada nos anos de 2014, 2015 e 2016. Somados, estes artigos totalizam 80 das 175 publicações entre 2008 e 2016, representand o cerca de 46\%. Outra análise possível é em relação às revistas que mais publicam na disciplina de Ciências Sociais, tendo maior representatividade a Revista Iberoamericana de Ciencia, Tecnologia y Sociedad (CTS), da Argentina, com 17 artigos, assim como a Revista Ra Ximhai, do México.

Os resultados para os artigos publicados por revistas de disciplinas ligadas à administração e contabilidade foram de 162 publicações, estando o tema de desenvolvimento regional e universidade bastante atrelados ao contexto da administração e contabilidade. O maior número de publicação sobre o tema ocorreu em 2012 e 2015, com, respectivamente, 27 e 26 publicações. A fim de relacionar as revistas que mais publicaram na disciplina de administração e contabilidade, observa-se que grande parte das publicações nesta área é de responsabilidade da Revista Gestão Universitária na América Latina (GUAL), do Brasil, com 42 publicações, o que representa 26\% das publicações na área.

No mesmo sentido, ao comparar as três disciplinas (áreas) de publicação - administração e contabilidade, ciências sociais e finanças e economia -, identifica-se que, ao longo dos anos, há pequenas oscilações nas publicações quanto ao tema de desenvolvimento regional atrelado à universidade, sendo em 2015 o maior número de publicações (59). Entretanto não se difere muito dos anos anteriores, 2014, 2013 e 2012. Com esse mesmo propósito, ao comparar as revistas e periódicos das três áreas, foi possível identificar que o Brasil é o país que mais produz cientificamente sobre o tema, com publicações na Revista Gestão Universitária na América Latina (GUAL), com 42 artigos, seguido da Argentina e do México, ambos com 17 publicações nos periódicos Revista Iberoamericana de Ciencia, Tecnologia y Sociedad (CTS) e Revista Ra Ximhai, respectivamente.

Contudo, como o objetivo proposto era o de realizar a revisão bibliométrica na plataforma Redalyc, foi possível delimitar as revistas que mais desenvolvem trabalhos quanto ao escopo da pesquisa, auxiliando, assim, o pesquisador a determinar quais periódicos e artigos serviriam de base para o desenvolvimento do tema.

\section{CONSIDERAÇÕES}

O desenvolvimento regional, atrelado ao papel das universidades, constitui-se em um tema que vem ganhando destaque ao longo dos anos, tendo em vista que o desenvolvimento, por si só, representa uma forma de consolidar as regiões e fomentar a competitividade. Por outro lado, as universidades vêm cada vez mais ocupando espaços sociais de transformação da realidade local, por meio do desenvolvimento social/humano gerado por meio da educação, da pesquisa e da extensão.

Em relação às publicações internacionais, identificadas na plataforma Scopus, foi possível observar que, a partir de 2013, houve um crescimento linear no número de publicações, sendo a Regional Studies o periódico com mais publicações na área de desenvolvimento regional e universidade, considerando que, entre os cinco analisados, é o único que possui ao menos um artigo publicado por ano indicado na análise. Além disso, constatou-se que a maioria das instituições que mais publicaram sobre o tema está situada no Reino Unido.

Já as publicações nacionais, analisadas a partir do território da América Latina, e por isso identificadas na plataforma Redalyc, demonstraram que o tema de desenvolvimento regional e 
universidade vem sendo discutido, principalmente, nas áreas de administração e contabilidade, economia e finanças e ciências sociais, sendo esta a com maior volume de publicações. Ao comparar as três áreas, observa-se que o periódico de destaque nas publicações relacionadas ao desenvolvimento regional e universidade é a Revista Gestão Universitária na América Latina (GUAL), que apontou o Brasil como o país que mais produziu sobre o tema.

Além disso, a base de dados para a pesquisa dos trabalhos internacionais possibilitou o acesso aos artigos de maior destaque na área. Por meio dessa informação, foi possível identificar que as principais publicações relacionaram o papel da universidade junto ao desenvolvimento regional voltado para a transferência de tecnologia, evidenciando o caráter de difusão científica e tecnológica das Instituições de Ensino Superior. De um modo geral, os artigos internacionais mais citados no tema seguem a mesma linha de pensamento, ao analisar o envolvimento das universidades com a região em que estão inseridas, com a discussão de questões referentes a contribuições na área de transferência tecnológica, pesquisa, de transferência do conhecimento, articulação com as empresas locais e o desenvolvimento econômico.

Entretanto é relevante destacar que, apesar de o número de publicações relacionadas ao tema de desenvolvimento regional e universidade ter ganhado certa evidência nos últimos anos, ainda há carência de pesquisas que discutam de forma mais aprofundada a relação e interferência das Instituições de Ensino Superior como um todo no desenvolvimento regional. Por fim, podese afirmar que os estudos sobre as universidades e seus papéis diante do desenvolvimento regional evidenciam a importância destas instituições como atores de articulação da sociedade, capazes de transformar a realidade local por meio da formação de recursos humanos e da difusão de conhecimento científico e tecnológico, a fim de contribuir com o desenvolvimento socioeconômico e cultural da região em que estão inseridas.

Pode-se considerar como limitação do estudo o fato de este ter utilizado somente duas bases de dados para pesquisa, Scopus e Redalyc, assim como o fato de que esta última não fornece as mesmas análises da Scopus, que permite maior profundidade na pesquisa. Para uma análise mais aprofundada sobre os autores e trabalhos mais citados, é necessário que seja feita uma busca manual, a qual não foi possível realizar neste estudo devido ao limite de tempo. Por esta razão, sugere-se que estudos futuros sobre esta natureza possam destinar maior amplitude de pesquisa, adotando outras bases de dados, assim como realizar a análise manual das informações obtidas nessas bases, no intuito de poder comparar, complementar ou substituir os resultados encontrados nesta pesquisa.

\section{REFERÊNCIAS}

ARAÚJO, C. A. Bibliometria: evolução histórica e questões atuais. Em Questão, Porto Alegre, RS, v. 12, n. 1, p. 11-32, jan./jun. 2006.

BASSAN, D. S.; SIEDENBERG, D. R. Desenvolver buscando a redução das desigualdades. In: BECKER, D. F.; WITTMANN, M. L. Desenvolvimento regional: abordagens interdisciplinares. Santa Cruz do Sul, RS: EDUNISC, 2003.

CECCHI, N. R.; LAKONICH, J.; PÉREZ, D.; ROTSTEIN, A. El compromiso social de la universidad latinoamericana siglo XXI. Entre el debate y la acción. Buenos Aires: IEC-CONADU, 2011.

CHIARELLO, I. S. A universidade e seu papel no desenvolvimento regional: contribuições do PROESDE. Revista Extensão em Foco, Caçador, SC, v. 3, n. 1, p. 240-57, 2015. 
DALLABRIDA, V. R. Teorias do desenvo/vimento: aproximações teóricas que tentam explicar as possibilidades e os desafios quanto ao desenvolvimento de lugares, regiões, territórios ou países. Curitiba: CRV, 2017.

DALLABRIDA, V. R. O desenvolvimento regional: a necessidade de novos paradigmas. Ijuí, RS: Ed. UNIJUÍ, 2000.

ELSEVIER. About Scopus. 2017. Disponível em: https://www.elsevier.com/solutions/scopus. Acesso em: 5 out. 2017.

ETZKOWITZ, H. Reconstrução criativa: hélice tripla e inovação regional. Revista Inteligência Empresarial, n. 23, abr./maio/jun. 2005.

HERNÁNDEZ-ARTEAGA, R. I.; MORA-GARCÍA, J. P.;y LUNA, J. A. Universidad y empresa: un binomio de responsabilidad social en el siglo XXI. Revista Tendencias, San Juan de Pasto, Colômbia, v. 28, n. 1, p. 14558, jan./jun. 2017.

HERNÁNDEZ-ARTEAGA, R. I.; ALVARADO-PÉREZ, J. C.; LUNA, J. A. Responsabilidad social en la relación universidad-empresa-Estado. Educación y Educadores, Bogotá, Colômbia, v. 18, n. 1, p. 95-110, jan./abr. 2015. DOI: http://dx.doi.org/10.5294/edu.2015.18.1.6.

MADUREIRA, E. M. P. Desenvolvimento regional: principais teorias. Revista Thêma et Scientia, Cascavel, PR, v. 5, n. 2, p. 8-23, jul./dez. 2015.

OLIVEIRA, G. B. Uma discussão sobre o conceito de desenvolvimento. Revista FAE, Curitiba, v. 5, n. 2, p. 37-48, maio/ago. 2002.

PÉREZ, M.; GIL, L. Caracterización de experiencias de responsabilidad social universitaria de universidades de la Red Latinoamericana de Cooperación Universitaria. In: DE VILLA, E. (Ed.). Responsabilidad social de las universidades. Buenos Aires: Fundación Red Latinoamericana de Cooperación Universitaria, 2012. p. 9-52.

PRODANOV, C. C.; FREITAS, E. C. Metodologia do trabalho científico: métodos e técnicas da pesquisa e do trabalho acadêmico. 2. ed. Novo Hamburgo, RS: Feevale, 2013.

SANDRONI, P. (Org.). Novíssimo dicionário de economia. São Paulo: Best Seller, 1999.

VÁZQUEZ BARQUERO, A. Desenvolvimento endógeno em tempos de globalização. Porto Alegre: Fundação de Economia e Estatística, 2001.

XAVIER, T. R.; INÁCIO, R. O.; WITTMANN, M. L.; KERN, J. O estudo do desenvolvimento regional: uma análise da produção científica internacional e dos "hot-topics". Gestão \& Regionalidade, São Caetano do Sul, SP, v. 29, n. 87, p. 19-31, set./dez. 2013.

\section{Sobre os autores:}

Mariane Rodrigues Volz de Aguiar: Cursando Mestrado Profissional em Gestão de Organizações Públicas pela Universidade Federal de Santa Maria (UFSM), RS. Tecnóloga em Gestão Pública pelo Instituto Federal Farroupilha - Campus São Vicente do Sul. Assistente em Administração no Instituto Federal Farroupilha - Campus São Vicente do Sul, exercendo atividades junto à Diretoria de Planejamento e Desenvolvimento Institucional. Tem experiência na área de Administração, com ênfase em administração pública, planejamento institucional e gestão 
estratégica, atuando principalmente nos seguintes temas: administração pública, gestão estratégica e desenvolvimento e gestão de pessoas. E-mail: marianeaguiarnra@gmail.com, Orcid: https://orcid.org/0000-0002-8196-8616

Sheila Kocourek: Doutora, mestre e graduada em Serviço Social pela Pontifícia Universidade Católica do Rio Grande do Sul (PUCRS). Professora associada do Departamento de Serviço Social, da Universidade Federal de Santa Maria (UFSM), RS. Exerce a chefia do Departamento de Serviço Social da UFSM. Editora-chefe da Revista Sociais e Humanas, da UFSM. Coordenou o Programa de Residência Multiprofissional Integrada em Sistema Público de Saúde, da UFSM.

E-mail: sheilakocourek@gmail.com, Orcid: https://orcid.org/0000-0001-8962-8758

Jairo da Luz Oliveira: Doutor, mestre e graduado em Serviço Social pela Pontifícia Universidade Católica do Rio Grande do Sul (PUC-RS). Professor adjunto IV no curso de Serviço Social na Universidade Federal de Santa Maria (UFSM); coordenador do Núcleo de Estudos, Pesquisa e Extensão em Gerontologia, Serviço Social e Saúde (NEPEGSSS), tendo como estudos os seguintes temas: formação profissional em Serviço Social, população em situação de rua, gerontologia social crítica, saúde e gestão pública; Tutor de Núcleo em Serviço Social e Saúde Mental na Residência Multiprofissional em Saúde Mental na UFSM; pesquisador bolsa PET Saúde/PET GraduaSUS; professor convidado na Especialização em Direitos Humanos e Serviço Social junto ao Curso de Serviço Social da Universidade Federal do Pampa (UNIPAMPA); professor do Programa de PósGraduação em Gestão de Organizações Públicas (UFSM). E-mail: jairooliveira.ufsm@gmail.com, Orcid: https://orcid.org/0000-0002-5006-4614

Adriano Correia Rodrigues: Especialista em Finanças Empresariais pela Universidade Luterana do Brasil (ULBRA). Graduado em Administração pela Universidade Federal de Pelotas (UFPel). Graduado em Ciências Contábeis pela Universidade Católica de Pelotas (UCPel). Tutor presencial na Universidade Luterana do Brasil - Polo Pelotas. Assistente administrativo na Universidade Federal do Pampa, Campus Jaguarão. Atuou como gerente administrativo na Fundação de Apoio Universitário, em Pelotas, instituição ligada à Universidade Federal de Pelotas. E-mail: rodriguescadriano@gmail.com, Orcid: https://orcid.org/0000-0002-7126-2660 